\title{
ANALISIS USAHA DAN PROSPEK BUDIDAYA JAHE GAJAH (Zingiber officinale) DI DESA KEMU KECAMATAN PULAU BERINGIN, KABUPATEN OKU SELATAN
}

\author{
Muridin \\ Sekolah Tinggi Ilmu Pertanian Belitang \\ Jln.Kampus Pertanian No.3 Belitang Kab.OKU Timur Prov.Sumatera Selatan \\ e-mail: muridin43@gmail.com
}

\begin{abstract}
SUMMARY
Business Analysis and Prospect of Plant Cultivation Elephant Ginger (Zingiber officinale R) in Desa Beringin Island Kemu District of South OKU District. The purpose of this study was to calculate the amount of income and financial feasibility of farming ginger in Desa Beringin Island Kemu District of South OKU District. The choice of location is done intentionally (purposive) conducted in October 2015. Sampling was done by using purposive sampling method on 20 samples of 100 population who undertake the cultivation of ginger in the village Kemu with the criteria of the respondents had sought cultivation of ginger> 5 years and wide land $>\mathrm{M}^{2}$.

Hasil 1000 study showed that the total cost of production dikelu arkan in the cultivation of ginger in one cropping cycle (9 months) in 2015 amounted to Rp 14,834,059, total receipts amounted to Rp 39.222188 so that the total income received amounted $\mathrm{Rp} 24,388,128$. NPV is Rp 19,211,923, IRR amounted to 54.54\% and the Net B / C was 1.9 indicating that the cultivation of ginger in Desa Beringin Island Kemu District of South OKU District feasible (feasible) to be developed so it has good prospects in the future to be developed.
\end{abstract}

Keywords: Analysis, Prospects, Ginger elephant, was developed.

\section{PENDAHULUAN}

\section{A. Latar Belakang}

Sejak tahun 1999 Pulau Jawa adalah penghasil utama jahe di Indonesia dengan sentra produksi Propinsi Jawa Barat dan Jawa timur, sebelum tahun 1999 sentra propinsi adalah pulau Sumatera terutama propinsi Bengkulu dan Sumatera Utara, dan sebagian propinsi Sumatera Selatan. Usaha jahe yang dilakukan di daerah tersebut pada waktu itu adalah sebagian besar lahan exs gambut yang kaya akan hara tanpa disertai dengan input produksi yang memadai, penanaman terus menerus menyebabkan lahan miskin akan unsur hara dan berdampak pada penurunan produktivitas, penurunan pendapatan petani dan tanaman mudah terserang oleh penyakit.

Kondisi tersebut menyebabkan sentra produksi jahe dari Sumatera pindah ke Jawa dan ditunjang oleh berkembangnya industri jamu dan pelabuhan yang berpusat di Jawa. Sebagai salah satu negara tropis di Asia Tenggara. Indonesia berpeluang mengembangkan tanaman ditinjau dari segi lingkungan dan sumber daya, namun, Indonesia belum mampu untuk menjaga kestabilan negara sebagai pengekspor jahe. Sehingga perlu adanya peningkatan budidaya jahe sebagai komoditi ekspor dan untuk kebutuhan domestik. Jahe diusahakan hampir diseluruh wilayah di Indonesia yang merupakan salah satu jenis tanaman obat dan dapat juga berfungsi sebagai rempah yang telah lama dikenal oleh masyarakat, kegunaan jahe adalah untuk bumbu, campuran makanan/minuman, obat-obatan, minyak wangi dan kosmetika.

Diantara tanaman obat, jahe merupakan salah satu komoditas yang menempati banyak di minati untuk keperluan jamu, industri obat, bumbu, posisi penting dalam perekonomian Indonesia, karna merupakan tanaman obat yang diekspor. Pada tahun 2017 diperkirakan konsumsi jahe segar untuk bumbu mencapai 20.742 ton/tahun dan untuk jamu gendong 12.088 ton/tahun, selain industri jamu, beberapa industri yang menggunakan jahe sebagai bahan baku adalah industri kerupuk, minuman, makanan, dari coklat dan kembang gula serta industri, farmasi.

Subsektor pertanian yang banyak menghasilkan devisa bagi negara ialah tanaman hortikultura, salah satunya yaitu yang berasal dari kelompok rimpang. Kelompok rimpang dari tanaman biofarmaka Indonesia yang ditujukan untuk ekspor mencapai 9 jenis meliputi: jahe, kunyit, laos/lengkuas, kencur, temulawak, lempuyang, temuireng, temukunci, dan dringo/dlingo dengan produksi terbesar dimiliki oleh tanaman jahe. Berdasarkan catatan Badan Pusat Statistik (2017) yang ditampilkan dalam Tabel 1, jahe menduduki peringkat pertama dengan persentase produksi terbesar diantara ke sembilan tanaman obat-obatan kelompok rimpang tersebut yaitu sebesar 47,37 persen (BPS 2017).

Tabel 1. Produksi Tanaman Obat-obatan Kelompok Rimpang Tahun 2017.

\begin{tabular}{llrr}
\hline No & Komoditi & $\begin{array}{c}\text { Produksi } \\
\text { (Ton) }\end{array}$ & $\begin{array}{r}\text { Persentase } \\
(\%)\end{array}$ \\
\hline 1 & Jahe & 274,57 & 47,37 \\
2 & Kunyit & 111,92 & 19,16 \\
3 & Laos/Lengkuas & 62,03 & 10,62 \\
4 & Kencur & 36,79 & 6,30 \\
5 & Temulawak & 52,80 & 9,04 \\
6 & Lempuyang & 12,53 & 2,14 \\
7 & Temuireng & 21,02 & 3,59 \\
8 & Temukunci & 10,19 & 1,74 \\
9 & Dringo/Dlingo & 7,31 & 1,25 \\
\hline \multicolumn{2}{l}{ Total } & $\mathbf{5 8 3 . 8 4}$ & $\mathbf{1 0 0 , 0 0}$ \\
\hline
\end{tabular}

Sumber: Badan Pusat Statistik (2017).

Terkhusus Provinsi Sumatera Selatan, kini sentra penghasil jahe terdapat di Kabupaten OKU Selatan dengan jumlah produksi $1,073,498 \mathrm{Kg}$ pada tahun 2013, tabel 2 menunjukkan perkembangan produksi jahe setiap kabupaten di Propinsi Sumatera Selatan selama empat tahun terakhir. 
Tabel 2. Perkembangan Produksi Jahe di Kabupaten OKU Selatan..

\begin{tabular}{|c|c|c|c|c|}
\hline No & Kecamatan & $\begin{array}{c}\text { Luas } \\
\text { Tanam } \\
\text { (Ha) }\end{array}$ & $\begin{array}{l}\text { Luas } \\
\text { Panen } \\
(\mathrm{Ha})\end{array}$ & $\begin{array}{l}\text { Produksi } \\
(\mathrm{Kg})\end{array}$ \\
\hline 1 & Muaradua & 0,6 & 0,5 & 6.315 \\
\hline 2 & Tiga Dihaji & 2,16 & 2,14 & 33.623 \\
\hline 3 & Buai Runjung & 2,2 & 2,1 & 30.043 \\
\hline 4 & Runjung Agung & 4,1 & 3,9 & 63.043 \\
\hline 5 & Muaradua Kism & 1,5 & 1,4 & 21.062 \\
\hline 6 & Buai Sandang Aji & 2,5 & 2,4 & 35.957 \\
\hline 7 & Kisam Tinggi & 3,1 & 2,9 & 47.935 \\
\hline 8 & Kisam Ilir & 2,3 & 2,3 & 36.157 \\
\hline 9 & Pulau Beringin & 18,9 & 18,8 & 365.148 \\
\hline 10 & Sindang Danau & 0,48 & 0,48 & 7.826 \\
\hline 11 & Sunagi Are & 3,8 & 3,7 & 62.173 \\
\hline 12 & Buai Rawan & 2,9 & 2,8 & 44.043 \\
\hline 13 & Buai Pemaca & 4,6 & 4,5 & 79.958 \\
\hline 14 & Buana Pemaca & 3,3 & 3,2 & 55.353 \\
\hline 15 & Simpang & 1,5 & 1,4 & 20.132 \\
\hline \multirow[t]{2}{*}{16} & Banding Agung & 2,3 & 2,2 & 35.643 \\
\hline & Warkuk & 2,2 & 2,1 & \\
\hline 17 & Selatar & & & 37.028 \\
\hline \multirow[t]{2}{*}{18} & Mekakau Ilir & 2.9 & 2,8 & 47.928 \\
\hline & Pematang & 2.7 & 2,6 & \\
\hline \multirow[t]{2}{*}{19} & Ribu & & & 44.138 \\
\hline & Jumlah & 64,04 & 62,22 & 1.073 .505 \\
\hline
\end{tabular}

Dinas Pertanian Tahun Kabupaten OKU Selatan 2018.

Desa Kemu juga merupakan Desa pertama yang menanam jahe gajah dalam sekala yang cukup luas di Kabupaten OKU Selatan mulai tahun 1988 sampai sekarang yang terus berkembang kedesa-desa dan kecamatan lainya di Kabupaten OKU Selatan.

\section{B. Rumusan Masalah}

Permasalahan yang akan diangkat dalam penelitian ini adalah:

1. Seberapa besar biaya produksi dan pendapatan yang dikelolah oleh petani dalam satu kali proses produksi?

2. Apakah kegiatan budidaya jahe di desa Kemu layak untuk dikembangkan?

\section{Tujuan dan Kegunaan}

1. Untuk mengetahui seberapa besar produksi dan pendapatan usaha tani jahe gajah layak diusahakan atau tidak.

2. Untuk menganalisis apakah budidaya jahe gajah layak dikembangkan di desa Kemu.

Penelitian ini diharapkan berguna sebagai pertumbuhan dalam usaha mengembangkan usahatani jahe gajah dimasa yang akan datang. Gambaran mengenai usaha tani jahe gajah di Kabupaten OKU Selatan khususnya Desa Kemu Kecamatan Pulau Beringin sebagai bahan refrensi bagi peneliti selanjutnya.

\section{KERANGKA PEMIKIRAN}

\section{A. Tinjauan Pustaka}

1. Konsep Agribisnis
Agribisnis merupakan semua kegiatan sektor pertanian mulai dari penyediaan sarana poduksi. Penanganan pasca panen, pengolahan, dan pemasaran sehingga produk tersebut sampai ke konsumen. Suatu satuan usaha agribisnis bisa berada disektor input pertanian atau ada disektor produksi pertanian dan ada juga sektor output pertanian. Perencanaan yang matang merupakan syarat bagi perkembangan suatu agribisnis sehingga bisa bersaing dengan perusahaan lain baik dalam sekala kecil, menengah maupun besar (Sjarkowi, 2004).

\section{Prospek}

Prospek adalah suatu gambaran keseluruhan, baik ancaman ataupun peluang dari kegiatan pemasaran yang akan datang yang berhunbungan dengan ketidak pastian dari aktifitas pemasaran atau penjualan. Dengan demikian prospek merupakan kondisi yang akan dihadapi oleh para petani dimasa yang akan datang baik kecendrungan untuk meningkatkan usahataninya. Kondisi ini dipengaruhi oleh berbagai peluang dan ancaman yang dihadapi.

\section{Biaya Produksi}

Biaya produksi adalah semua pengeluaran yang akan dikeluarkan produsen untuk memperoleh faktor produksi yang akan digunakan agar produksi yang direncanakan akan berhasil. Biaya adalah jumlah uang yang akan dikeluarkan untuk semua proses produksi sampai produksi tersebut sampai dipasarkan.

\section{Konsep Penerimaan}

Soeharjo, (2010) menjelaskan bahwa penerimaan usahatani dapat berupa hasil penjualan produksi usahataninya, produksi yang dikonsumsi petani selama kegiatan usahatani dan kenaikan nilai investasi.

\section{Konsep Pendapatan}

Selanjutnya menurut Soeharjo, (2010) bahwa pendapatan merupakan selisih antara penerimaan dengan biaya yang dikeluarkan dan yang dalam suatu kegiatan untuk mendapatkan produksi dilapangan pertanian karena dalam kegiatan diatas petani bertindak sebagai pengelola. Sebagai penanam modal dan usahanya dalam usahatani maka pendapatan ini digambarkan sebagai balas jasa dari faktor-faktor produksi yang biasanya dihitung dalam jangka waktu tertentu.

\section{B. Botani dan Sistematika Tanaman Jahe}

1. Uraian Tanaman Jahe

a. Klasifikasi tanaman jahe menurut Sunanto (2010) adalah

$\begin{array}{ll}\text { Divisi } & \text { : Spermatophyta } \\ \text { - Sub-divisi } & \text { : Angiospermae } \\ \text { - Kelas } & : \text { Monocotyledoneae } \\ \text {. Ordo } & : \text { Zingiberales } \\ \text {. Famili } & : \text { Zingiberaceae } \\ \text { - Genus } & : \text { Zingiber } \\ \text {. Species } & : \text { Z officinale }\end{array}$

b. Deskipsi tananman jahe.

Tanaman berbatang semu, tinggi $30 \mathrm{~cm}$ sampai $1 \mathrm{~m}$, rimpang bila dipotong berwarna kuning atau jingga. 
Daun sempit, panjang 15-23 $\mathrm{mm}$, lebar 8-15 $\mathrm{mm}$ tangkai daun berbulu, panjang $2-4 \mathrm{~mm}$, bentuk lidah daun memanjang, panjang 7,5-10 $\mathrm{mm}$, dan tidak berbulu, seludang agak berbulu. Perbungaan berupa malai, berbentuk tongkat atau bundar telur yg sempit, 2,75-3 kali lebarnya, sangat tajam, panjang malai 3,5-5 $\mathrm{cm}$, lebar 1,5-1,75 cm, gagang bunga hampir tidak berbulu, panjang $25 \mathrm{~cm}$, rahis berbulu jarang, sisik pada gagang terdapat 5-7 buah, berbentuk lanset, letaknya berdekatan atau rapat, hampir tidak berbulu (Gembong, 1996).

\section{Syarat Tumbuh}

Tanaman jahe membutuhkan curah hujan relatif tinggi, yaitu antara 2.500-4.000 mm/tahun. Suhu udara optimum untkk budidaya tanaman jahe antara 20$35^{\circ} \mathrm{C}$. Jahe tumbuh baik di daerah tropis dan subtropis dengan ketinggian 1-2.000 $\mathrm{m} \mathrm{dpl}$.

\section{Model Pendekatan}

Model pendekatan yang digunakan dalam penelitian ini adalah model pendekatan secara diagramatis.

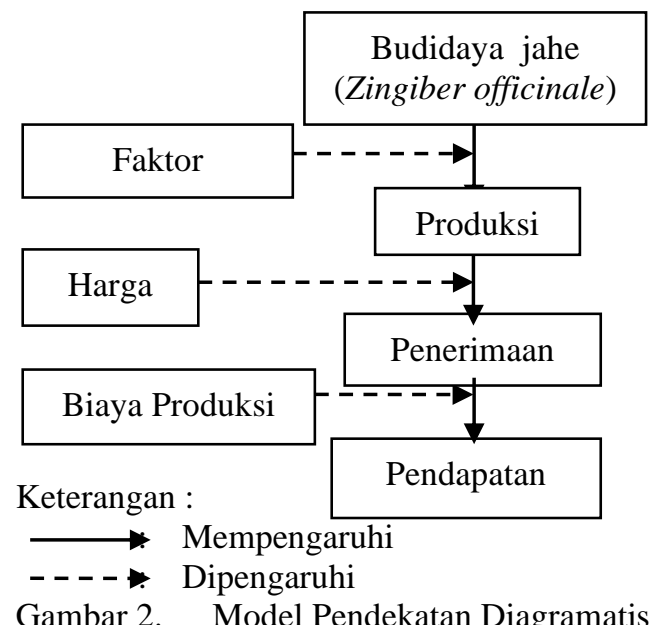

\section{Hipotesis}

Berdasarkan rumusan masalah dan tujuan dari penelitian ini maka diajukan hipotesis sebagai berikut :

1. Bahwa biaya produksi yang dikeluarkan dalam usahatani jahe gajah lebih kecil dibandingkan dengan penerimaan sehingga diperoleh pendapatan.

2. Bahwa usahatani jahe gajah di Desa Kemu Kecamatan Pulau Beringin Kabupaten OKU Selatan menguntungkan dan layak untuk dikembangkan.

\section{E. Batasan-Batasan}

1. Petani yang dijadikan contoh dalam penelitian ini adalah petani yang telah mengusahakan budidaya jahe gajah > 5 tahun dan memiliki luas lahan antara $1.000-$ $5.000 \mathrm{M}^{2}$.

2. Produksi jahe yang di peroleh dan dijual adalah dalam bentuk jahe segar yang baru dipanen $(\mathrm{Kg})$.

3. Harga adalah satuan finansial yang disepakati antara penjual dan pembeli pada saat penelitian ( $R p)$.

4. Biaya total produksi adalah seluruh biaya yang dikeluarkan dalam satu kali proses produksi atau biaya tetap ditambah biaya variabel $(\mathrm{Rp} / \mathrm{Ha} / \mathrm{MT})$.
5. Pendapatan usahatani adalah keuntungan petani jahe dari penerimaan produksi (hasil) yang telah dikurangi biaya-biaya selama proses produksi di ukur dengan satuan (Rp/Ha/MT).

6. Proses produksi adalah lamanya waktu yang dibutuhkan dalam budidaya tanaman jahe (9 bulan).

7. R/C Ratio adalah nilai yang menunjukkan besarnya perbandingan penerimaan dengan setiap rupiah biaya yang dikeluarkan dalam budidaya tanaman jahe.

8. Analisa kelayakan usaha menggunakan analisis NPV, IRR dan Net B/C

\section{METODE PENELITIAN}

\section{A. Tempat dan Waktu}

Penelitian ini telah dilaksanakan di Desa Kemu, Lokasi penelitian dipilih secara sengaja (purposive), mengingat desa tersebut merupakan satu diantara sentral produksi jahe gajah di Kecamatan Pulau Beringin Kabupaten OKU Selatan. Penelitian telah dilaksanakan pada Bulan Oktober 2019.

\section{B. Metode Penelitian dan Penarikan Contoh}

Metode penarikan contoh yang digunakan dalam penelitian ini adalah secara sengaja dan tertuju (purposive sampling) terhadap 20 orang petani contoh dari seluruh populasi yang berjumlah 100 orang petani jahe di Desa Kemu Kecamatan Pulau Beringin OKU Selatan. Adapun kriteria pengambilan contoh adalah petani jahe yang memiliki luas lahan $>1.000 \mathrm{M}^{2}$ dan telah memiliki pengalaman berusaha budidaya tanaman jahe $>5$ tahun.

\section{Metode Pengumpulan Data}

Data yang dikumpulkan terdiri dari data primer dan data sekunder. Data primer diperoleh dari hasil observasi dan wawancara langsung dengan petani contoh, sedangkan data sekunder diperoleh dari Dinas Pertanian Tanaman Pangan dan Hortikoltura Kabupaten OKU Selatan

\section{Metode Pengolahan Data}

Data yang diperoleh dari lapangan terlebih dahulu dikelompokan kemudian dianalisis secara matematis dan selanjutnya dijelaskan secara deskripsif.

1. Untuk menghitung biaya dan pendapatan petani digunakan rumus (Hernanto, 1997) :

$$
\mathrm{TC}=\mathrm{FC}+\mathrm{VC} \text {. }
$$

Dimana :

$\mathrm{TC}=$ Total Cost (Rp/proses)

$\mathrm{FC}=$ Fixed Cost (Rp/proses)

$\mathrm{VC}=$ Variabel Cost (Rp/proses)

1. Untuk mengetahui penerimaan, digunakan rumus :

$$
\mathrm{TR}=\mathrm{Y} \times \mathrm{P} \text {. }
$$

Dimana :

$\mathrm{TR}=$ Total Revenues (Rp/proses)

$\mathrm{Y}=$ Yield $(\mathrm{Kg} /$ proses $)$

$\mathrm{P}=$ Price $(\mathrm{Rp} / \mathrm{Kg})$

3. Untuk menghitung pendapatan, digunakan rumus :

$$
\mathrm{I}=\mathrm{TR}-\mathrm{TC}
$$

Dimana :

I $=$ Income $(\mathrm{Rp} /$ proses $)$ 
$\mathrm{TR}=$ Total Revenue $(\mathrm{Rp} /$ proses $)$

$\mathrm{TC}=$ Total Cost $(\mathrm{Rp} /$ proses $)$

4. $\mathrm{R} / \mathrm{C}$ ratio dihitung dengan menggunakan rumus .

$\mathrm{R} / \mathrm{C}$ ratio $=$

Dimana $: \quad \underline{\mathrm{TR}}$
$\mathrm{R} / \mathrm{C}=$ Return $(\quad \mathrm{TC}$
$\mathrm{TR}=$ Total Revenues (Rp/proses)
$\mathrm{TC}=$ Total Cost (Rp/proses)

5. Untuk menghitung nilai net $\mathrm{B} / \mathrm{C}$ ratio maka digunakan rumus :

$$
\text { Net } \mathrm{B} / \mathrm{C}=\frac{\sum \mathrm{NB}(+)}{\sum \mathrm{NB}(-)}
$$

\section{HASIL DAN PEMBAHASAN}

\section{A. Keadaan Umum Wilayah}

Desa Kemu terletak di Kecamatan Pulau Beringin Kabupaten Ogan Komering Ulu (OKU) Selatan. Desa tersebut memiliki luas wilayah $4.305 \mathrm{Ha}$ yang terdiri dari pemukiman penduduk, pekarangan, lahan persawahan dan perkebunan.

Desa Kemu terdiri dari lahan kering dan lahan basah. Lahan kering digunakan untuk tanaman perkebunan, palawija, sedangkan lahan basah digunakan untuk tanaman padi sawah yang terdiri dari sawah irigasi teknis dan sawah tadah hujan. Penggunaan lahan di Desa Kemu sudah cukup merata, penggunaan lahan di Desa Kemu dapat dilihat pada tabel berikut :

Tabel 3. Penggunaan Lahan di Desa Kemu, 2019.

\begin{tabular}{clr}
\hline No. & Jenis Penggunaan Lahan & Luas Lahan $(\mathrm{Ha})$ \\
\hline 1. & Persawahan & 700 \\
2. & Perkebunan & 3.000 \\
3. & Pemukiman & 300 \\
4. & Pekarangan & 300 \\
5. & Perkantoran & 5 \\
\hline & Jumlah & 4.305 \\
\hline
\end{tabular}

Sumber : Monografi Desa Kemu, 2019.

Desa Kemu memiliki jumlah penduduk 4.794 jiwa dengan jumlah penduduk laki-laki 2.448 jiwa dan jumlah penduduk perempuan 2.346 jiwa dengan jumlah kepala keluarga $1.235 \mathrm{KK}$ dan kepadatan penduduknya 85 jiwa/Km.

Tabel 4. Jumlah Penduduk Desa Kemu.

\begin{tabular}{clc}
\hline No & \multicolumn{1}{c}{ Jenis kelamin } & Jumlah (Jiwa) \\
\hline 1. & Laki-laki & 2.448 \\
2. & Perempuan & 2.346 \\
\hline & Jumlah & 4.794 \\
\hline
\end{tabular}

Sumber : Monografi Desa Kemu, 2019.

Mata pencaharian penduduk Desa Kemu mayoritas sebagai petani. Potensi sumber daya alam khususnya yang ada di Desa Kemu sudah diupayakan pemanfaatannya oleh masyarakat, seperti sumber daya alam sawah dimanfaatkan untuk menanam padi saat musim tanam padi, lahan perkebunan sudah dimanfaatkan untuk menanam kopi, tembakau, karet, lada, jahe sayur mayur dan tanaman palawija lainnya.

\section{B. Profil Petani Contoh}

Responden pada penelitian ini merupakan penduduk yang berdomisili di Desa Kemu Kecamatan Pulau Beringin Kabupaten OKU Selatan, responden memiliki luasan lahan yang beragam. Dari hasil data lapangan yang diperoleh, luas lahan yang diusahakan oleh seluruh responden tidak ada yang lebih dari $5.000 \mathrm{M}^{2}(0,5 \mathrm{Ha})$. Menurut beberapa responden, modal usaha yang dibutuhkan untuk menanam jahe gajah cukup besar sehingga lahan yang digunakan tidak terlalu luas, hanya beberapa petani yang memiliki modal besar yang mampu menanam jahe gajah dengan lahan yang luas.

Tabel 5. Distribusi Responden Petani Jahe Berdasarkan Luasan Lahan

\begin{tabular}{cccc}
\hline $\begin{array}{l}\mathrm{N} \\
\mathrm{o}\end{array}$ & Luas lahan $\left(\mathrm{M}^{2}\right)$ & $\begin{array}{c}\text { Jumlah } \\
\text { (Orang) }\end{array}$ & $\begin{array}{c}\text { Persentase } \\
(\%)\end{array}$ \\
\hline 1 & $1.000-2.000$ & 10 & 50 \\
3 & $2.100-3.000$ & 2 & 10 \\
4 & $3.100-4.000$ & 5 & 25 \\
5 & $4.100-5.000$ & 2 & 10 \\
\hline & Jumlah & 30 & 100 \\
\hline
\end{tabular}

Sumber : Data Primer, 2019.

Berdasarkan data pada Tabel 5 di atas, dapat dilihat bahwa luas lahan petani jahe umumnya adalah berkisar antara 1.000 sampai $5.000 \mathrm{M}^{2}$. Adapun luas lahan terbanyak adalah $1.000-2.000 \mathrm{M}^{2}$ sebanyak 10 orang dengan persentase sebesar $50 \%$.

\section{Analisa Biaya Usahatani Jahe}

Biaya tetap yang digunakan oleh petani responden usahatani jahe di Desa Kemu Kecamatan Pulau Beringin diantaranya meliputi biaya sewa lahan dan biaya penyusutan peralatan yang dapat dilihat pada Tabel 6 sebagai berikut : Tabel 6. Biaya Tetap Budidaya Jahe di Desa Kemu, 2019.

\begin{tabular}{llcc}
\hline \multirow{2}{*}{ No } & Komponen Biaya & \multicolumn{2}{c}{ Nilai } \\
\cline { 3 - 4 } & $\begin{array}{c}\text { (Rp/Lg/Pr } \\
\text { oses) }\end{array}$ & (Rp/Ha/Proses) \\
\hline 1. & Sewa Lahan & 323.750 & 1.250 .000 \\
2. & Penyusutan Alat & 281.802 & 1.340 .022 \\
\hline & Total Biaya & & \\
& Tetap & 605.552 & 2.590 .022 \\
\hline
\end{tabular}

Sumber : Olahan Data Primer, 2019.

Kegiatan usahatani budidaya jahe di Desa Kemu Kecamatan Pulau Beringin, dalam penggunaan input lahan sebagian besar memiliki status kepemilikan lahan sendiri, sehingga dalam kaidah usahatani dianggap sebagai lahan sewa. Berdasarkan data di atas bahwa biaya sewa lahan petani dengan luas lahan rata-rata $2.590 \mathrm{M}^{2}$ atau seluas 0,26 Ha memerlukan biaya sebesar Rp 323.750/Lg/Proses atau sebesar Rp 1.250.000/Ha/Proses.

Biaya rata-rata penyusutan peralatan yang digunakan oleh petani responden adalah sebesar Rp 281.802/Lg/Proses atau sebesar Rp 1.340.022/Ha/Proses. Biaya tetap usahatani jahe di Desa Kemu yang terdiri dari biaya sewa lahan dan biaya penyusutan peralatan dengan rata-rata luas lahan 0,26 
Ha dalam satu kali proses produksi yaitu selama 9 bulan adalah sebesar $\mathrm{Rp} 605.552$ atau biaya tetap dengan luas lahan rata-rata $1 \mathrm{Ha}$ adalah sebesar Rp 2.590.022/Proses.

Tabel 7. Rata-rata Biaya Variabel Usahatani Jahe di Desa Kemu, 2019.

\begin{tabular}{cccc}
\hline \multirow{2}{*}{$\mathrm{N}$} & \multirow{2}{*}{ Komponen } & \multicolumn{2}{c}{ Nilai } \\
\cline { 3 - 4 } $\mathrm{O}$ & & $\mathrm{Rp} / \mathrm{Lg} /$ & $(\mathrm{Rp} / \mathrm{Ha} /$ \\
& & 3.878 .365 & 16.062 .116 \\
1. & Biaya Saprodi & 8.285 .500 & 32.551 .667 \\
\hline & Tenaga Kerja & 12.163 .865 & 48.613 .782 \\
\hline & Total Biaya Variabel &
\end{tabular}

Sumber : Olahan Data Primer, 2019.

Berdasarkan hasil pada Tabel 7, dapat diketahui bahwa rata-rata besarnya biaya sarana produksi dengan ratarata luas lahan $2.590 \mathrm{M}^{2}$ atau seluas 0,26 Ha adalah sebesar $\mathrm{Rp} 3.878 .365 / \mathrm{Lg} /$ Proses atau sebesar Rp 16.062.116/Ha/Proses. Adapun besarnya biaya tenaga kerja dalam satu kali proses ( 9 bulan) adalah sebesar Rp 8.285.500/Lg/Proses atau sebesar Rp 32.551.667/Ha/Proses. Besarnya biaya variabel kegiatan usahatani jahe di Desa Kemu yang terdiri dari biaya saprodi dan biaya tenaga kerja dengan luas lahan $2.590 \mathrm{M}^{2}$ atau seluas 0,26 Ha adalah sebesar Rp 12.163.865/Lg/Proses atau sebesar Rp 48.613.782/Ha/Proses.

Tabel 8. Biaya Total Usahatani Budidaya Jahe di Desa Kemu, 2019.

\begin{tabular}{clrr}
\hline & & \multicolumn{2}{c}{ Nilai } \\
\cline { 3 - 4 } No & Komponen & $(\mathrm{Rp} / \mathrm{Lg} /$ Proses $)$ & $(\mathrm{Rp} / \mathrm{Ha} /$ Proses $)$ \\
\hline 1. & Biaya Tetap & 605.552 & 2.590 .022 \\
2. & Biaya & 12.163 .865 & 48.613 .782 \\
& Variabel & & 51.203 .804
\end{tabular}

Sumber : Olahan Data Primer, 2019.

Berdasarkan hasil pada Tabel 8, dapat diketahui bahwa biaya tetap responden usahatani jahe di Desa Kemu dalam satu kali proses produksi dengan rata-rata luas garapan seluas $2.590 \mathrm{M}^{2}$ atau $0,26 \mathrm{Ha}$ adalah sebesar Rp 605.552 atau sebesar Rp 2.590.022/Ha/Proses. Biaya variabel responden usahatani jahe dalam satu kali proses produksi dengan rata-rata luas garapan $2.590 \mathrm{M}^{2}$ atau 0,26 Ha adalah sebesar Rp 12.163.865 atau sebesar Rp 48.613.782/Ha/Proses, sehingga diperoleh biaya total produksi usahatani jahe di Desa Kemu Kecamatan Pulau Beringin Kabupaten OKU Selatan dalam satu kali proses produksi (9 bulan) dengan rata-rata luas garapan seluas $2.590 \mathrm{M}^{2}$ atau seluas 0,26 Ha adalah sebesar Rp 12.769.418 atau biaya total produksi dalam satu kali proses dengan luas lahan $1 \mathrm{Ha}$ adalah sebesar Rp 51.203.804.

Harga jual jahe gajah pada saat penelitian bervariasi antar responden namun tidak terlalu jauh berbeda yaitu berkisar antara Rp 8.000 sampai Rp 10.000. Produksi, harga, penerimaan dan pendapatan yang diperoleh disajikan dalam Tabel 9 sebagai berikut :

Tabel 9. Produksi, Harga, Penerimaan dan Pendapatan Usahatani Jahe di Desa Kemu, 2019.

\begin{tabular}{cllc}
\hline No & \multicolumn{1}{c}{ Uraian } & \multicolumn{1}{c}{ Satuan } & Nilai \\
\hline 1. & Produksi & $\mathrm{Kg} / \mathrm{Lg} /$ Proses & 4.548 \\
2. & Harga & $\mathrm{Rp} / \mathrm{Kg}$ & 8.625
\end{tabular}

\begin{tabular}{cllr} 
3. & Penerimaan & $\mathrm{Rp} / \mathrm{Lg} /$ Pross & \multicolumn{1}{c}{39.157 .500} \\
4. & Penerimaan & $\mathrm{Rp} / \mathrm{Ha} /$ Proses & 153.000 .000 \\
5. & Biaya Produksi & $\mathrm{Rp} / \mathrm{Lg} /$ Proses & 12.769 .418 \\
6. & Biaya Produksi & $\mathrm{Rp} / \mathrm{Ha} /$ Proses & 51.203 .804 \\
7. & Pendapatan & $\mathrm{Rp} / \mathrm{Lg} /$ Proses & 26.388 .082 \\
8. & Pendapatan & $\mathrm{Rp} / \mathrm{Ha} /$ Proses & 101.796 .196 \\
9. & $\mathrm{R} / \mathrm{C}$ Rasio & $\mathrm{Rp}$ & 2,99 \\
\hline
\end{tabular}

Sumber : Olahan Data Primer, 2019.

Berdasarkan hasil pada Tabel 9, dapat diketahui bahwa rata-rata produksi jahe gajah yang dihasilkan oleh responden dalam satu kali proses produksi (9 bulan) dengan luas lahan $2.590 \mathrm{M}^{2}$ atau 0,26 $\mathrm{Ha}$ adalah sebanyak $4.548 \mathrm{Kg}$. Penggunaan bibit jahe berbeda-beda diantara responden walaupun dengan luas lahan yang sama terkadang penggunaan bibitnya berbeda. Hal ini dipengaruhi oleh besar kecilnya bibit saat persemaian. Semakin kecil bibit maka akan semakin banyak mata bibit yang dihasilkan. Faktor lain yang berpengaruh adalah kualitas bibit dan jarak tanam.

Harga jual jahe pada saat penelitian berkisar antara Rp 6.000 sampai dengan $\mathrm{Rp} 10.000$ dengan rata-rata harga jual jahe gajah adalah sebesar Rp $8.625 / \mathrm{Kg}$. Umumnya petani melakukan penjualan jahe gajah secara langsung kepada pedagang pengepul yang berada di Desa Kemu atau pedagang pengepul yang berada di Kecamatan Pulau Beringin bahkan sampai ke kota Medan. Adanya perbedaan harga jual jahe ini dipengaruhi oleh waktu panen.

Pada saat awal panen biasanya harga jual jahe lebih murah karena produksi masih sedikit sehingga waktu untuk mengumpulkan jahe menjadi lebih lama sehingga banyak mengalami penyusutan. Biasanya dibutuhkan waktu 7 sampai 10 hari untuk memenuhi pesanan sebanyak 1 truk. Pada saat panen raya maka harga jual jahe menjadi lebih mahal karena pengumpulan jahe menjadi lebih mudah dan lebih cepat untuk dikirim ke pedagang besar yang ada di luar Kabupaten bahkan di luar Propinsi Sumatera Selatan. Pada saat panen raya biasanya hanya dibutuhkan waktu 2 sampai 3 hari untuk memenuhi pesanan sebanyak 1 truk sudah dapat terpenuhi sehingga tidak terlalu tinggi mengalami penyusutan. Harga jual jahe juga dipengaruhi oleh kualitas jahe yang dihasilkan.

Rata-rata penerimaan usahatani jahe gajah dengan luas lahan garapan 0,26 Ha dalam satu kali proses produksi adalah sebesar Rp 39.157.500 atau penerimaan sebesar Rp 153.000.000/Ha/Proses. Penerimaan responden dipengaruhi oleh produksi jahe yang dihasilkan dan harga jual jahe. Penerimaan juga dipengaruhi jauh dekatnya lokasi lahan dengan pengepul. Jarak tempuh berpengaruh dengan biaya pengangkutan yang ahrus dikeluarkan oleh responden. Semakin jauh lokasi lahan maka semakin besar biaya yang harus dikeluarkan untuk upah pengangkutan sehingga akan mengurangi penerimaan.

Pendapatan yang diterima oleh petani dalam usahatani jahe gajah di Desa Kemu dalam satu kali proses produksi dengan luas lahan rata-rata $0,26 \mathrm{Ha}$ adalah sebesar Rp 26.388.082 atau apabila besarnya pendapatan dikonversikan ke dalam hektar maka pendapatan sebesar Rp 101.796.196/Ha/Proses.

Nilai R/C rasio usahatani jahe gajah dalam satu kali periode usahatani (9 bulan) adalah sebesar Rp 2,99. Nilai 
$\mathrm{R} / \mathrm{C}$ rasio sebesar 2,99 berarti bahwa setiap satu rupiah biaya yang dikeluarkan untuk kegiatan usahatani jahe gajah maka akan memberikan penerimaan sebesar Rp 2,99. Nilai $\mathrm{R} / \mathrm{C}>1$ ini menunjukan bahwa kegiatan usahatani jahe gajah yang dilakukan oleh petani responden di Desa Kemu Kecamatan Pulau Beringin Kabupaten OKU Selatan menguntungkan.

\section{E. Analisa Kelayakan Usaha}

Kriteria kelayakan dari proyek ini adalah: Proyek layak jika NPV bertanda positif dan sebaliknya tidak layak jika NPV bertanda negatif.

Tabel 10. Analisa NPV Usaha Budidaya Jahe di Desa Kemu Kecamatan Pulau Beringin Kab OKU Selatan, 2019.

\begin{tabular}{|c|c|c|c|c|c|}
\hline 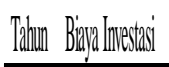 & Bexya Opersonal & Totalcost & Benefti & NetBeneft & DF 18\%" PrexatitValue 189 \\
\hline $0 \quad 20.131 .100$ & 0 & 20.613.100 & 0 & $\cdot 20,6113,100$ & 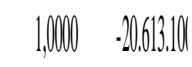 \\
\hline 1 & 127.769.418 & 12.769,418 & 26.3980.082 & 13.618 .6605 & 0,8775 \\
\hline 2 & 13.4977.888 & 13,4077.888 & 27.707.187 & 149299,98 & $0,7182 \quad 10,2609,74$, \\
\hline 3 & $14,708.183$ & 14.778 .883 & 29,092861 & 15.014 .578 & $9,138,301$ \\
\hline 4 & 14.782 .197 & 14.78 .197 & 30.577 .04 & $15,763.307$ & 6.991 .160 \\
\hline j & $15,521,007$ & $15,521,107$ & $32,074.879$ & 165535072 & 4. 40103.80. \\
\hline & & & & Milial IP & $21,691,26$ \\
\hline
\end{tabular}

Sumber : Olahan Data Primer, 2019.

Hasil analisis pada Tabel 10 diperoleh nilai investasi awal untuk pembelian lahan dan alat-alat produksi adalah sebesar Rp 20.613.100 sehingga pendapatan pada tahun ke 0 adalah Rp -20.613.100. Dari perhitungan NPV selama lima tahun dengan tingkat bunga $18 \%$ maka diperoleh nilai NPV adalah sebesar Rp 21.613.269 dan nilai NPV > 0, hal ini menunjukan bahwa usahatani jahe gajah di Desa Kemu Pulau Beringin OKU Selatan menguntungkan dan layak untuk dikembangkan.

Tabel 11. Analisa Perhitungan IRR Usaha Budidaya Jahe di Desa Kemu Kecamatan Pulau Beringin Kabupaten OKU Selatan, 2019.

\begin{tabular}{cccccr}
\hline Tahun & Net Benefit & DF 18\% & Present Value 18\% & DF 33\% & Present Value 33\% \\
\hline 0 & -20.613 .100 & 1,0000 & -20.613 .100 & 1,00000 & -20.613 .100 \\
1 & 13.618 .665 & 0,8475 & 11.541 .241 & 0,75188 & 8.677 .625 \\
2 & 14.299 .598 & 0,7182 & 10.269 .749 & 0,56532 & 5.805 .726 \\
3 & 15.014 .578 & 0,6086 & 9.138 .336 & 0,42505 & 3.884 .295 \\
4 & 15.765 .307 & 0,4371 & 6.891 .161 & 0,24029 & 1.655 .900 \\
5 & 16.553 .572 & 0,2660 & 4.403 .882 & 0,10214 & 449.803 \\
\hline \multicolumn{7}{c}{ NPV } & 21.631 .269 & & -139.751 \\
\hline \multicolumn{7}{c}{}
\end{tabular}

$$
\begin{aligned}
& \mathrm{IRR}=\quad \mathrm{i} 1+\frac{\mathrm{NPV}+}{(\mathrm{NPV}+)-(\mathrm{NPV}-)} \quad \mathrm{x}(\mathrm{i} 2-\mathrm{i}) \\
& \mathrm{IRR}=18+\frac{21.631 .269}{21.771 .019} \times(33-18) \\
& =18+\frac{21.631 .269}{21.771 .019} \times(15) \\
& =18+0,993580886 \quad \times \quad(15) \\
& \begin{array}{lll}
= & 18+14,90371329
\end{array} \\
& \text { il }<\text { IRR }<\text { i2 } \\
& 18 \%<32,9<33 \%
\end{aligned}
$$

Berdasarkan hasil perhitungan, diperoleh nilai IRR adalah sebesar 32,9 yang berarti nilai IRR > nilai suku bunga bank/Social Opportunity Cost of Capital (SOCC) sebesar $18 \%$. Hal ini menunjukan bahwa usahatani jahe gajah di Desa Kemu Pulau Beringin OKU Selatan menguntungkan dan layak (feasibel) untuk dikembangkan.

Tabel 12. Analisa Net B/C Usaha Budidaya Jahe di Desa Kemu.

\begin{tabular}{crrr}
\hline Tahun & \multicolumn{1}{c}{ Net Benefit } & DF 18\% & Present Value 18\% \\
\hline 0 & -20.613 .100 & 1,0000 & -20.613 .100 \\
1 & 13.618 .665 & 0,8475 & 11.541 .241 \\
2 & 14.299 .598 & 0,7182 & 10.269 .749 \\
3 & 15.014 .578 & 0,6086 & 9.138 .336 \\
4 & 15.765 .307 & 0,4371 & 6.891 .161 \\
5 & 16.553 .572 & 0,2660 & 4.403 .882 \\
\hline
\end{tabular}

$\begin{aligned} \text { Net B/C } & =\frac{\sum(\overline{\mathrm{NB}})(+)}{\sum(\overline{\mathrm{NB}})(-)} \\ & =\frac{42.244 .369}{20.613 .100} \\ & =\frac{30.949 .326}{20.613 .100} \\ & =1,501\end{aligned}$

Hasil perhitungan, diperoleh nilai Net B/C sebesar 1,5. Nilai Net B/C 1,5 berarti bahwa setiap Rp 1 biaya yang dikeluarkan untuk usaha budidaya jahe maka akan menghasilkan benefit atau keuntungan sebesar Rp 1,5. Nilai Net B/C > 1 menunjukkan bahwa usahatani jahe gajah di Desa Kemu Kecamatan Pulau Beringin Kabupaten OKU Selatan menguntungkan dan layak (feasibel) untuk dikembangkan.

\section{KESIMPULAN DAN SARAN}

\section{A. Kesimpulan}

Berdasarkan hasil penelitian dan analisis yang telah dilakukan, maka dapat ditarik kesimpulan sebagai berikut ;

1. Biaya total produksi yang dikeluarkan dalam usaha budidaya jahe gajah dalam satu kali siklus produksi adalah sebesar Rp 12.769.418, total penerimaan selama satu kali siklus produksi adalah sebesar Rp 39.157.500 sehingga pendapatan yang diterima adalah sebesar Rp 26.388.082. Nilai R/C rasio adalah sebesar 2,99 menunjukan bahwa usaha budidaya jahe gajah menguntungkan.

2. Nilai NPV adalah sebesar Rp 21.613.269, nilai IRR adalah sebesar 32, 9\% dan nilai Net B/C adalah sebesar 1,5 yang menunjukkan bahwa usaha budidaya jahe gajah di Desa Kemu Kecamatan Pulau Beringin Kabupaten OKU Selatan layak (feasible) untuk dikembangkan. 


\section{B. Saran}

Adapun saran yang dapat disampaikan oleh penulis adalah : usahatani jahe cukup menguntungkan maka usaha ini perlu dikembangkan dan dikelola lebih baik dan lebih intensif lagi dengan menerapkan teknologi dalam budidayanya dan penegendalian hama penyakit sehingga dapat meningkatkan hasil produksi dan pendapatan petani.

\section{DAFTAR PUSTAKA}

Anonim, 2010. Dinas Perkebunan Sumatra Sealatan. 2014. Dinas Pertanian Kabupaten OKU Selatan

Badan Pusat Statistik, 2007. Statistik Industri Besar dan sedang, Bahan Baku, Jakarta

Daniel M, 2010. Metode penelitian Sosial Sosial Ekonomi Dilengkapi Beberapa Alat Analisa dan Penentuan Penggunaan. PT.Buini Aksara. Jakarta.

Farri B, Paimin, Murhananto, 1999. Budi Daya, Pengolahan, Pengolahan Jahe,Edisi Revisi,Cetakan ke. IX, Penebar Swadaya.

Ibrahim, Y. 2009. Studi Kelayakan Bisnis. Rineka Cipta. Jakarta

Kadarsan, 2010. Ilmu Usaha Tani. FP. UGM. Yogyakarta

Sjarkowi F dan Sufri, M. 2004. Manajemen Agribisnis. C.V.Baldad Garififi Press.

Palembang.

Soeharjo, A dan Patong, D. 2000. Sendi-Sendi Pokok Ilmu Usaha Tani.

Departemen Imu-Ilmu Sosial Ekonomi Pertanian. Fakultas Pertanian Institut Pertanian Bogor.

Suratman, dkk, 2007. Pedoman Bercocok Tanam Jahe (Zingiber Officinale Rosc), Sirkulair No. 39, Balittro, Bogor.

Tohir, K, A. 2009.Usaha Tani Indonesia (1). Remeka Cipta. Jakarta. 